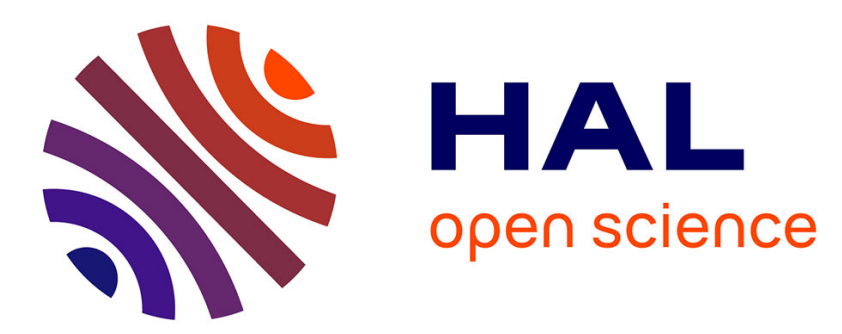

\title{
The meaning of sport and performance among amateur and professional athletes
}

Anthony Piermatteo, Grégory Lo Monaco, Gersende Reymond, Marc Eyraud, Lionel Dany

\section{- To cite this version:}

Anthony Piermatteo, Grégory Lo Monaco, Gersende Reymond, Marc Eyraud, Lionel Dany. The meaning of sport and performance among amateur and professional athletes. International Journal of Sport and Exercise Psychology, 2018, pp.1-13. 10.1080/1612197X.2018.1536160 . hal-02527772

\section{HAL Id: hal-02527772 \\ https://hal-amu.archives-ouvertes.fr/hal-02527772}

Submitted on 1 Apr 2020

HAL is a multi-disciplinary open access archive for the deposit and dissemination of scientific research documents, whether they are published or not. The documents may come from teaching and research institutions in France or abroad, or from public or private research centers.
L'archive ouverte pluridisciplinaire HAL, est destinée au dépôt et à la diffusion de documents scientifiques de niveau recherche, publiés ou non, émanant des établissements d'enseignement et de recherche français ou étrangers, des laboratoires publics ou privés. 


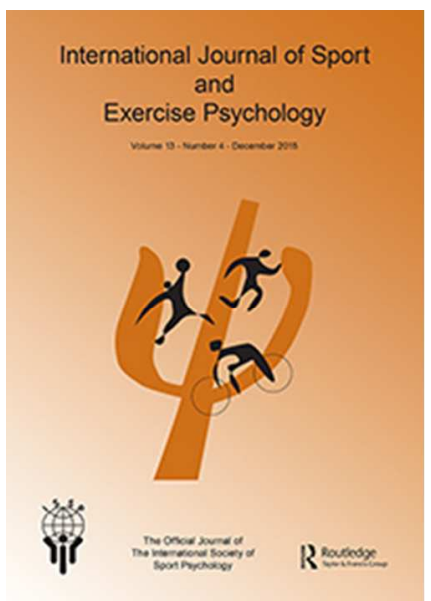

\section{The Meaning of Sport and Performance Among Amateur and Professional Athletes}

\begin{tabular}{|r|l|}
\hline Journal: & International Journal of Sport and Exercise Psychology \\
\hline Manuscript ID & RIJS-2017-0138.R1 \\
\hline Manuscript Type: & Original Article \\
\hline Keywords: & $\begin{array}{l}\text { sport, performance, social representations, amateur athletes, professional } \\
\text { athletes }\end{array}$ \\
\hline
\end{tabular}

\section{SCHOLARONE ${ }^{m}$}

Manuscripts 


\title{
The Meaning of Sport and Performance Among Amateur and Professional Athletes
}

\begin{abstract}
This paper investigates the meaning of sport and performance for amateur and professional athletes through the social representations theory. From this perspective, this study focuses on the content associated with sport and performance through word association tasks conducted with 421 amateur athletes and 64 professional athletes. Prototypical and similarity analyses showed that concerning amateur athletes, hedonism and health constitute important components of these representations. Concerning professional athletes, while sport is mainly structured around hedonism and togetherness, performance appears to be articulated around an effort/reward dichotomy. Moreover professional athletes' social representations of sport and performance only encompass a marginal reference to health. These results help to identify the motivations which may underpin the practice of sport among amateur and professional athletes.
\end{abstract}

Keywords: sport; performance; social representations; amateur athletes; professional athletes. 
What are sport and performance? What is the meaning of these two concepts? While most of the studies focused on the meaning of sport and performance consist of theoretical reflections about these concepts (Frey, 1991; Segrave, 2000), this study aims to answer these questions by drawing on the social representations theory (Moscovici, 1961/2008). In line with this social psychological theory "concerned with meaning and its interpretation" (Wagner et al., 1999, p. 104), the object does not matter and understanding the relationship to it is more important (Moscovici, 1982). From this perspective we will focus on the study of social representations (SR) of sport and performance among amateurs and professional athletes. In fact, considering these two different groups could enable us to study these two concepts as the result of a social construction. Indeed, the investigation of the meaning of sport and performance has not been extensively documented in the field of sport psychology, while in the field of the social representations theory, only a few contributions can be noted (Lacassagne, Bouchet, Weiss, \& Jebrane, 2004; Lacassagne, Pizzio, \& Jebrane, 2006; Stewart \& Lacassagne, 2005). Moreover, the results of these studies, which were only focused on the SR of sport, indicate that performance may be a complementary concept to sport and could be underpinned by specific values. Thus, through drawing on the theoretical and methodological framework of the social representation theory, this study aims to update the results related to the study of the meaning of sport (Mrazek and Schäfer, 1988). It also aims to extend the results highlighted in the field of the SRs' theory (Lacassagne, et al., 2004, 2006; Stewart \& Lacassagne, 2005) by taking into account the concept of performance and the population of professional athletes for whom this object is an important issue in the practice of sport (Douglas \& Carless, 2009).

\section{The Theory of Social Representations}


SRs can be defined as "systems of opinions, knowledge and beliefs particular to a culture, a social category, or a group with regards to objects in the social environment" (Rateau, Moliner, Guimelli, \& Abric, 2011, p. 478). SRs are not an objective definition of reality, they rather constitute a socially constructed and shared knowledge, "a created reality appropriated by a group and integrated into its system of values" (Stewart \& Lacassagne, 2005 , p. 723 ). In more simple terms, they refer to the way individuals see the various social objects of their environment (e.g., family, work, health, etc.). However, more than just images of these objects, SRs are involved in individuals' and groups' behaviors and position taking toward them as they provide guidelines regarding what to say or what to do with regard to the object (Abric, 1993; Moscovici, 1982; Rateau et al., 2011). Thus, the way one pictures an object such as a sport determines, to some extent, one's practices related to this activity.

As for their organization, according to the central core theory (Abric, 1993, 2001) SRs can be considered as an interconnected set of cognitive elements that are structured around a central core and a peripheral system, these two subsets being characterized by specific properties (Abric, 1993). The first of these subsets, the central core, includes the most consensual content. This content generates and organizes the meaning of the overall representation, and is characterized by high stability as it is relatively insensitive to context variations (Abric, 1993; Rateau et al., 2011).

Beyond the central core, the peripheral elements allow SRs to be adapted to different contexts. Peripheral elements can vary easily and are also characterized by interindividual variations (Abric, 1993). This distinction between central and peripheral elements helps to explain the fact that although various contents (i.e., knowledge, opinions or beliefs) are widely shared among the members of a given group, there are also differences from one individual to another. This also accounts for the fact that although these shared aspects seem 
almost immutable, the way a group represents a given object can still evolve (Abric, 1993; Guimelli, 1993).

\section{Social Representations of Sport and Performance}

As Mrazek and Schäfer (1988) noted, trying to explain "the rising amount of time spent on sporting activities and the growing popularity of the words 'athletic' and 'fit' in everyday life $[\ldots]$ inevitably leads to the question of what is actually meant by sport" (p. 109). Even though this statement about the trend of fitness was published in the late 1980's, the same phenomenon of a growing culture of fitness and wellness seems to be current (Johansson \& Andreasson, 2014; Kickbusch \& Payne, 2003; Sassatelli, 2011, 2013). In this context, the assumption that "sport is good for health" is commonplace (Murphy \& Waddington, 1998; Safai, 2008; Scambler, 2005). However, while the fact that health and well-being are associated with sport appears to be consensual (Murphy \& Waddington, 1998), other elements may compose the general definition of this object. Thus, as defined by Coakley and Donnelly (2004), sport encompasses notions of competition, rigorous physical exertion and complex physical skills. However, such a definition, as formulated by experts in a specific field, may not match the representation held by other groups, such as athletes themselves, be they amateur or professionals. Indeed, as defined by Rateau et al. (2011) an SR is specific to a particular group. As a consequence, there is not just one definition of sport and the meaning of this activity may be different from one group to another.

Yet, the investigation of meaning has not been extensively documented in the field of sports psychology (Mrazek \& Schäfer, 1988; Seippel, 2006). However, a few contributions can be noted (see Table 1). Among these, the research of Seippel (2006), which is based on 1660 questionnaires focused on the meaning of sport, showed that sport was mainly associated with "fun", the desire to "keep fit", to benefit from "mental recreation" and to 
enhance "social relations". Moreover, for the participants of this study - who were amateur athletes - competition was one of the least important reasons for doing sport. These findings and the comparisons between different groups of amateur athletes led Seippel (2006) to conclude that people experience their sports activities very differently. However, the questionnaires used in Seippel's study consisted in a list of various reasons for doing sport and participants were asked to rate these reasons regarding their own sports activity. This type of procedure restricts responses to a pre-established set of choices while some reasons that were not anticipated by the author may exist among the studied sample. In order to establish the meaning associated with sport on the basis of participants' responses, Mrazek and Schäfer (1988) used a word association task (Authors, 2015; Authors, 2016). According to this task, participants were asked to associate the words that came to their mind when thinking about the word "sport". On this basis, Mrazek and Schäfer (1988) showed that six categories of associations were associated with sport: (a) the sports activities that participants had in mind; (b) the positive evaluation of this activity; (c) game, play and leisure; (d) training and effort; (e) achievement and competition; and (f) school. However, such results may need to be updated. Indeed, this research was conducted in two high schools in the USA and the Federal Republic of Germany almost 30 years ago. Moreover, as the word association task was just one measure among others in their study, the authors did not conduct an extended analysis of participants' associative responses (see Authors, 2016 for a presentation of the methods for studying word associations in the field of SRs).

\section{Insert Table 1 about here}

In the field of SRs two contributions focused on sport can be noted: a comparison between French and Moroccan students in the field of sport (Lacassagne et al., 2004; Stewart 
\& Lacassagne, 2005) and a comparison between athlete and non-athlete students (Lacassagne, et al., 2006). Two of these studies (Lacassagne et al., 2004, 2006) used word association tasks. They concluded that the SR of sport among French students in the field of sport is composed of two dimensions: A hedonistic dimension where training and competition are linked to pleasure and leisure and a dimension related to professional sport where performance is associated with performance enhancing drug use. These results are partly similar to those of Seippel (2006) who also observed that participants tend to associate competition with pleasure. However, unlike the results of the other studies on the meaning of sport, the theme of performance appeared in participants' answers. For Lacassagne et al. (2004), this result is related to modern values of sport. These modern values are focused on competition and performance as a way to improve individuals both at the psychological and physiological level. They are the consequence of a competitive logic associated with highlevel sports and their large-scale media coverage. On this basis, performance seems to be a complementary concept to sport. Indeed, although linked to sport, performance seems to be underpinned by specific values and could therefore diverge from the meaning of sport which tends to be associated with pleasure and health (Murphy \& Waddington, 1998, Seippel, 2006). From this perspective, performance, as well as sport, may be studied as an SR, especially for professional athletes for whom this object is an important issue in the practice of sport (Douglas \& Carless, 2009). However, although the results of Lacassagne et al. (2004, 2006) refer to professional athletes, no study focused on the meaning of sport or performance seems to have been conducted on such a population.

Consequently, this study aims to study the meaning of sport and performance among amateur and professional athletes. From this perspective, we used the theoretical and methodological framework of SRs to address the way in which these populations perceive these two objects. More precisely we investigated the content associated with sport and 
performance and the way this content is organized. Moreover, we can draw the hypothesis that this content and its organization may differ from one group of athletes to another. Indeed, Seippel (2006) observed that competitive levels could affect the meaning attributed to sport and Lacassagne et al. (2006) showed that sport is not represented in the same way by sports students (i.e., students of the sciences and techniques of sport and physical activities) and non-sports students (i.e., students of business management). Thus, on the basis of the results of previous studies (Lacassagne et al., 2004, 2006; Mrazek and Schäfer, 1988; Seippel, 2006) content related to health and hedonism should be more associated by amateur athletes while professional athletes' social representations of sport and performance should be more oriented toward competition and the ways to achieve performance.

\section{Material and Methods}

The sample of this study consisted of 64 professional athletes registered in different sports clubs such as basket-ball, volley-ball and rugby (41 men, 23 women, $M_{\text {age }}=19.70$ years, $S D=4.45)$ and 421 participants in a French amateur running race $(10 \mathrm{~km}, 298 \mathrm{men}, 123$ women, $M_{\text {age }}=44.67$ years, $\left.S D=10.84\right)$. The amateur athletes were asked by the organizers of the event, a local sports association, to complete an online questionnaire while professional athletes had to complete a printed version.

The first section of the questionnaire dealt with participants' characteristics (i.e., gender, age and sporting practice). On the basis of these questions, it appeared that amateur and professional athletes differed significantly in terms of training times per week. Indeed, while amateurs had on average 3.77 training sessions per week $(S D=2.11)$, professional athletes had 5.66 training sessions $(S D=2.08), F(1,481)=44.30, p<.001, \eta p^{2}=.08$. This difference was also found regarding the average number of hours per week and indicates a 
more intense practice for professionals $(M=11.43, S D=3.65)$ than for amateurs $(M=5.50$, $S D=3.21), F(1,481)=180.79, p<.001, \eta p^{2}=.27$.

The second section of the questionnaire was focused on the gathering of the SRs of sport and performance. Participants had to answer a word association task. Word association tasks are widely used in the field of SRs (Authors, 2015; Ernst-Vintila, Delouvée, \& RolandLévy, 2011; Jung \& Pawlowski, 2014, 2015; Authors, 2016; Mäkiniemi, Pirttilä-Backman, \& Pieri, 2011; Lebrun, 2014; Authors, 2013; Authors, 2014; Pozzi, Fattori, Bocchiaro, \& Alfieri, 2014; Roland-Lévy, Lemoine, \& Jeoffrion, 2014; Tavani, Zenasni, \& Pereira-Fradin, 2009). This task consisted in asking participants to associate three words concerning the term "sport" and then three words regarding the term "performance". More precisely, "sport" and "performance" were given to participants as priming words and they were asked to write the three words "that came to their mind" in reference to each of these two terms (see Authors, 2015; Authors, 2016). As for data analysis, this method allows prototypical analyses and similarity analyses to be conducted (see Authors, 2016 or Jung \& Pawlowski, 2014, 2015 for a recent example of similarity analysis).

\section{Prototypical analysis.}

Based on the central core theory (Abric, 1993, 2001), the prototypical analysis (Authors, 2015; Bonnec, Roussiau, \& Vergès, 2002) aims to highlight the salience of certain elements of the representation (i.e., the words associated by participants) by cross-tabulating two independent criteria: the frequency of occurrence of an element and its appearance ranking (Authors, 2015). On the basis of the distinction between the high and low values relative to these two criteria, one can build a $2 \times 2$ table $^{1}$. Thus, the most common elements

\footnotetext{
${ }^{1}$ Within the framework of a double-entry table, two other cases can be considered (i.e., low frequency/low appearance ranking, low frequency/high appearance ranking). However, as these cases tend to present more ambiguous information (Bonnec et al., 2002) for the sake of clarity we chose to focus on the cells characterized by a high frequency.
} 
and those among the first to be mentioned in the associative chain (low appearance ranking) are considered as the most salient and are part of the central zone of the table (Danermark, Englund, Germundsson, \& Ratinaud, 2014). This cell encompasses the elements that are most likely to be part of the central core of the SR under study. Conversely, the elements with a high frequency and a high appearance ranking are considered as potential peripheral elements ${ }^{2}$.

\section{Similarity analysis.}

This method is based on a conception of SRs as a set of cognitive elements interconnected with each other (Authors, 2016). It therefore aims to show the relationships between the elements of a given SR. These relationships can be expressed through an index of co-occurrence which quantify the extent to which two words are connected. It refers to the number of participants who, among their answers to the verbal association task, associated the same pair of words. Thus, two words characterized by a high value of co-occurrence can be considered as highly connected as a large number of participants associated these words with the inductive term (i.e., in the case of this contribution: sport or performance). This analysis allows a graphic representation of this organisation called the maximum tree to be established. This graph constitutes the socio-cognitive structure of the object under study.

\section{Results}

\section{Prototypical analysis.}

\footnotetext{
${ }^{2}$ The term "potential" means that, in order to conclude that a representational element is central or peripheral, the verbal association task is not sufficient and must be completed by a questionnaire dedicated to the diagnostic of the structural status (Guimelli, 1993; Moliner, 2002). However, within the framework of this research our aim was not to confirm the structural status of the elements but rather to investigate the content of the SRs.
} 
For the first step of our analysis, following the recommendations formulated in the literature (Bonnec et al., 2002; Authors, 2016) the content related to word association tasks was grouped into categories on the basis of semantic proximity and processed through a prototypical analysis. The results are reported in Table 2 and 3.

\section{Insert Table 2 about here}

Concerning amateur athletes (see Table 2) the results show that content associated with sport by amateur athletes is mainly focused on the topic of health. Thus, "health" and "well-being" along with "pleasure" are part of the central zone of the table which regroups the potentially central elements of amateur athletes' SR of sport. As such, it appears that these elements are likely to constitute the most consensual characteristics of sport for this population (Abric, 1993). Moreover, another element linked to health can be observed in the peripheral zone of the table (i.e., healthy body). Other elements such as "surpassing oneself" (i.e., overcoming one's own limitations) and "togetherness" are also associated by participants. As potentially peripheral, these elements are characterized by a high frequency of association. However, contrary to the elements of the central zone of the table, these elements are characterized by a higher appearance ranking (i.e., on average, they tend to appear later in the responses to the word association task). As a consequence, although this potential peripheral status may lead us to consider this content as less essential than "health", "well-being", and "pleasure" in the way that amateur athletes see sport, they seem to constitute a more concrete manifestation of these notions and help to specify their meaning (Abric, 1993). Thus, on the whole, amateur athletes' SR of sport seems to be composed of four general categories of content: health, hedonism (for the elements of the central zone), surpassing oneself and a social dimension (for the elements of the peripheral zone). 
Concerning the SR of performance, "pleasure" is also present in the central zone of the table, as well as "escape". It appears that, according to these two elements, the SR of performance may be organized around content related to hedonism. As for the peripheral zone of the table, secondary aspects of this representation refer to more practical content related to the achievement of performance (i.e., surpassing oneself, training).

\section{Insert Table 3 about here}

Concerning the SR of sport of professional athletes, the results (see Table 3) indicate that "pleasure" along with "effort" and various "sports activities" (e.g., soccer, volley-ball, etc.) are potentially central elements of professional athletes' SR of sport. In other words, in line with the resultats of Mrazek and Schäfer (1988), for these participants, sport refers to a large set of sports activities and seems to be mainly defined through a dichotomy between hedonism and effort. At the peripheral level, sport refers to "togetherness", "competition" and "values". Here, togetherness, which refers to a social dimension of sport, is reported by a high frequency of participants but is generally considered as less salient in its appearance ranking than other content. Thus, to professional athletes, this social dimension, as well as the values pertaining to sport and competition, could be considered as secondary aspects of their representation of sport.

Concerning performance, professional athletes' SR seems to be articulated around an "effort/reward" dichotomy where essential (central) aspects are related to the dimension of effort (e.g., "training", "effort") and peripheral aspects to the dimension of reward (i.e., "results"). Moreover, while sport is perceived as a pleasing activity that encompasses a social dimension (i.e., togetherness), performance seems to be more self-centered with a central 
zone which refers to surpassing oneself and the ways of achieving this goal (i.e., "training" and "effort").

\title{
Similarity analysis.
}

Concerning amateur athletes, the results of the similarity analysis (see Figure 1) indicate that the SR of sport is mainly structured around the notions of "health" and "pleasure". This result is in line with the prototypical analysis which indicated that these two elements may be characterized by a central status. Indeed, as central elements define the general meaning of the whole SR, they are therefore expected to be characterized by a high associative value (i.e., a high number of connections with the other elements, Abric, 2001). These two notions which are strongly interconnected are themselves linked to other content of the SR of sport. Thus, "health" is connected to similar notions such as "well-being", "healthy body and mind" but also to "escape" and "leisure". These two last connections, as well as the relationship between "release" and "well-being", indicate that, for amateur athletes, part of the positive impact of sport on health may come from its ability to offer a way of escape and release. The other pole of the representation, "pleasure", is connected to two classes of content. On the one hand, to the social dimension of sport through the term "togetherness", but also to "surpassing oneself" and other content similar to the latter element. Thus, amateur athletes' SR of sport includes notions such as "effort", "competition", "training” or "surpassing oneself", however this content seems to be seen through the lens of pleasure.

\section{Insert Figure 1 about here}

\author{
Regarding the SR of performance, although the prototypical analysis identified \\ "escape" and "pleasure" as potentially central elements, the similarity analysis indicated that
}


the SR is structured around the notions of training and surpassing oneself. Indeed, these two elements are characterized by a high associative value. However, each of these notions is associated with one of the potentially central elements with a high level of co-occurrence. Thus, "training" is mainly associated with "escape" $(n=35)$ while "surpassing oneself" is mainly associated with "pleasure" $(n=25)$. On the whole, it appears that both of these two poles are associated with content that refers to health (e.g., "health" is associated with "training" while "well-being", "healthy mind and body" are connected to "surpassing oneself'). However, amateur athletes' SR of performance mainly encompasses content oriented toward the achievement of performance such as "effort", "improvement", "results", "pain", "equipment" and "technique". This content, as well as the terms "training" and "surpassing oneself" which seem to organize the whole SR, indicates that for amateur athletes performance is seen as a self-centered goal which can be achieved through training and effort.

\section{Insert Figure 2 about here}

With regard to professional athletes the results of the similarity analysis (see Figure 2) show an SR of sport structured around the notions of pleasure, competition and togetherness. While togetherness and pleasure are characterized by a higher connexity and thus seem to help generate the meaning of the whole representation, competition is strongly linked to each of these two notions. Moreover, togetherness is associated with "values" and, to a lesser extent, with "effort" and "sports activities". We can assume that, as the sample was composed of professional athletes in team sports, this aspect helps to regulate their SR, leading participants to represent sport as a team thing (in the word association task, mainly team sports were associated as sports activities). Thus, "effort" and "values" through their link with "togetherness" appear to be associated with this collective context. In the same way, 
"surpassing oneself" which tends to be, by definition, a self-centered concept, is also associated with "togetherness". As a consequence, teams may be seen as a means of improving and excelling oneself.

The other pole, "pleasure", is associated with "leisure" and to a lesser extent with "pain", "training" and "health". At this level, one should note that even though health related notions are linked to both of these poles (i.e., "healthy-mind" is related to "togetherness" and "health" to "pleasure"), they are characterized by a low frequency of association.

Concerning the SR of performance, this is structured around the notions of "surpassing oneself", "training", "effort" and "results". In line with the effort/reward dichotomy observed in the word associations, in this network, "surpassing oneself" is the most salient element, to which are associated the means of achieving performance (i.e., "training" and "effort") and the "results"- which can be considered as the expression of performance. Thus, with regard to the means, while "effort" is associated with "rigor", "technique" and "training", the SR of sport is associated with "pleasure", but also with "motivation", "abilities" and "values". As for the expression of performance, "surpassing oneself" is associated with the notion of "goal", and also with other elements that seem to express performance such as "results", “improvement” and "competition”.

\section{Discussion}

The research presented in the framework of this contribution aimed to identify how amateur and professional athletes perceive sport and performance. Using the SRs' approach we were able to observe that each of these groups is characterized by a specific representation of these two objects. Thus, hedonism is an essential component of amateur athletes' SRs of sport and performance, and health related content constitutes a major part of these SRs (some of this content may be characterized by a central status), especially the SR of sport. These 
results are in line with those of Seippel (2006) who observed that "joy/fun" and "keep fit", are two of the main elements associated with sport by participants from voluntary sport associations. Thus, amateurs' SRs of sport and performance appear to be in line with a postmodern evolution of the meaning of sport toward a hedonistic perspective (Bodet, 2009; Lacassagne et al., 2004). Indeed, according to these authors the meaning of sport tends to be redefined. This redefinition implies a change from the Olympic motto "faster, higher, stronger" and de Coubertin's philosophy focused on performance and competition to "an increasing aspiration for hedonistic, fun, natural, plural, self-determined and unconstrained practices" (Bodet, 2009, p. 227). Moreover, although performance, by definition, could be expected to have a meaning which would fit de Coubertin's philosophy, the prototypical analysis revealed "hedonistic" content such as "escape" and "pleasure" as potential central elements of this SR.

Similarly to amateurs' SRs, which tend to fall within a post-modern definition of sport, the SRs of this activity among professional athletes also encompass the notion of pleasure as a potential central element. Moreover, considering the potential influence of the collective practice of sport of these participants, their SR of sport also encompasses an important social dimension which, as suggested by similarity analysis, could contribute to the organization of this representation and to the definition of its meaning. Indeed, in line with the theory of SRs (Rateau et al., 2011) these results show a specific perception which is associated with the context and issues which characterize professional athletes. Thus, participants' intensive practice of collective sport may explain the important place given to togetherness in their SR of sport. While this content does not appear in the central zone of the table resulting from the prototypical analysis, the similarity analysis allows us to infer the potential central status of this element which may then contribute to the generation of the meaning of the SR as a whole. The numerous connections between this element and the other 
content of the SR indicate that togetherness may be essential in the way professional athletes perceive and engage in sport and its various components such as effort and motivation, health, values, surpassing oneself and competition.

However, unlike amateur athletes, professional athletes' SRs of sport and performance only encompass a marginal reference to health. This difference can be explained by the fact that, while health may be an important motivation associated with sports activity for amateur athletes (Johansson \& Andreasson, 2014; Kickbusch \& Payne, 2003; Sassatelli, 2011, 2013), for professional athletes the practice of sport seems to be mainly motivated by performance itself (Douglas \& Carless, 2009) and personal achievement (Van-Yperen \& Duda, 1999). Thus, for professional athletes, these goals as well as competitive practices may help to place their SR of performance within the framework of a modern perception of sport associated with de Coubertin's philosophy and focused on effort and competition. From this perspective, performance, through surpassing oneself, is associated with a goal (see Figure 2) towards which most of the content given by participants seems to be oriented. This result can be explained by the fact that performance constitutes the core of the modern sport philosophy as well as being a major issue in the practice of professional athletes. Within this framework, contrary to the important social dimension which characterizes the SR of sport, the SR of performance tends to be more self-focused as indicated by the important place accorded to surpassing oneself as a performance goal. As a consequence, the whole SR of performance appears to be articulated around an effort/reward dichotomy which associates the various means of achieving performance with this goal of surpassing oneself.

Thus, the results of this research have allowed us to update the data in the literature regarding the perception of sport. Moreover, the study of the SR of performance has provided extended information regarding this object but also regarding sport, as performance is an important issue in athletes' practice of sport (especially professional athletes). From this 
perspective, we gathered information about the perceptions of professional athletes, a population which is rarely approached in these kind of studies as it is not easily accessible (Lemyre, Roberts, \& Stray-Gundersen, 2007).

However, this research is characterized by some limitations. The first one relates to the comparison of the results of amateur and professional athletes. Although it could be tempting to compare these two populations' SRs of sport and performance, the characteristics of the samples of this research limit this approach to the data. Indeed, the two groups of participants are characterized by important differences regarding their mean age, and the type of sport they practice. Thus, the observed divergences in terms of SRs may be attributed to these differing characteristics of the samples. From this perspective, the presence of a social dimension in professional athletes' SR of sport may be attributed to their practice of a collective sport rather than to their professional status and could also have been found for amateur athletes if they were practising a collective sport. As a consequence, even though specific methodologies allow SRs to be compared (Authors, 2016), such analyses may be inconclusive within the framework of this contribution. However, as SRs are shaped by the history of the groups and their specific characteristics and contribute to "the taking of a position or a course of action" (Abric, 1993, p. 76), it appears more informative to understand the relationships between athletes (amateurs and professionals) and sport and performance than to compare these two groups regarding their SRs of these objects.

The second limitation relates to the accuracy of the similarity analyses regarding the meaning of the words associated with sport and performance. Indeed, similarity analysis is based on an index of co-occurrence which quantifies the extent to which two words are connected (Authors, 2016). However, the same word can be characterized by different meanings depending on individuals. Thus, although two words can be associated by a large number of participants - and therefore be characterized by a large index of co-occurrence- 
we cannot be sure that the meaning of these words, and, in consequence, the meaning of their relationship, is the same for all of them. This inability to distinguish the different meanings attributed to the same word is also the main limitation of word associations tasks, which allow us to collect the verbal material used to perform similarity analyses. However, this issue has already been discussed in the literature and improvements to word association tasks are currently under study (Authors, 2016).

Consequently, although these limitations call for further work in order to clarify these first exploratory results, this research provides the basis for the establishment of a link between the question of meaning and its social construction and the sporting practices of amateur and professional athletes. As SRs are conceptualized as a guide for practices (Abric, 2001), the study of SRs of sport and performance enlighten the understanding of athletes' sporting practices. For instance, the results associated with amateur athletes confirm the evolution of sporting practices toward a more recreational practice which encompasses health oriented motivations (Johansson \& Andreasson, 2014; Kickbusch \& Payne, 2003; Sassatelli, 2011, 2013). These results help us to understand the motivations which lead individuals to practice sport and which could be used within the framework of preventive communication campaigns. Indeed, research in the field of SRs has shown that SRs' content may be used in connection with communication campaigns. More precisely, according to their structural status, on the one hand, they can improve the efficiency of these campaigns to elicit targeted behaviors (Souchet \& Girandola, 2013), and on the other hand, authors (2016) have shown that threatening core cognitions produces more deleterious effects in terms of withdrawal behaviors than threatening peripheral ones.

In addition, the marginal presence of health related content in professional athletes' SRs along with an SR of performance focused on surpassing oneself and barely mentioning hedonism leads us to hypothesize that this population may be more prone to adopt risky 
behaviors such as trying to return to sport as soon as possible after an injury even when it is to the detriment of their physical well-being (Curry, 1993; Nixon, 1992; Podlog \& Eklund, 2005), or using performance enhancing drugs (Donovan, Egger, Kapernick, \& Mendoza, 2002 ; Simon, 1984). This hypothesis is in line with the assumptions of Pipe (2001) and Safai (2008) according to which performance goals related to competition issues are a pressure which may generate risky practices. From this perspective, future research could focus on the study of the link between the SRs of sport and performance and the sporting practices of athletes. In terms of applications in the field of prevention, identifying SRs of sport and performance according to the specific characteristics of professional athletes (e.g., type of sport, collective or individual sport, etc.) may help to identify risk factors which could allow us to adapt preventive action and coaching to these populations. Such perspectives highlight the relevance of the theory and methodologies of SRs in the field of sport psychology and the study of sporting practices. 


\section{References}

Abric, J.-C. (1993). Central system, peripheral system: their functions and roles in the dynamics of social representations. Papers on Social Representations, 2(2), 75-78.

Abric, J.-C. (2001). A structural approach to social representations. In K. Deaux \& G. Philogène (Eds.), Representations of the social (pp. 42-47). Oxford: Blackwell.

Bodet, G. (2009). Sport participation and consumption and post-modern society: from Apollo to Dionysus?. Society and Leisure, 32(2), 223-241.

Bonnec, Y., Roussiau, N., \& Vergès, P. (2002). Categorical and prototypical analysis: A study on the quality-process in hospital institutions. European Review of Applied Psychology, 52, 213-220.

Coakley, J., \& Donnelly, P. (2004). Sports in Society: Issues and Controversies. Toronto: McGraw-Hill.

Curry, T. J. (1993). A little pain never hurt anyone: Athletic career socialization and the normalization of sports injury. Symbolic Interaction, 16(3), 273-290.

Danermark, B., Englund, U., Germundsson, P., \& Ratinaud, P. (2014). French and Swedish teachers' social representations of social workers. European Journal of Social Work, 17(4), 491-507.

Donovan, R. J., Egger, G., Kapernick, V., \& Mendoza, J. (2002). A conceptual framework for achieving performance enhancing drug compliance in sport. Sports Medicine, 32(4), 269-284.

Douglas, K., \& Carless, D. (2009). Abandoning the performance narrative: Two women's stories of transition from professional sport. Journal of Applied Sport Psychology, 21(2), 213230.

Ernst-Vintila, A., Delouvée, S., \& Roland-Lévy, C. (2011). Under threat. Lay thinking about terrorism and the three dimensional model of personal involvement: a social psychological analysis. Journal of Risk Research, 13, 297-325.

Frey, J. H. (1991). Social risk and the meaning of sport. Sociology of Sport Journal, 8(2), 136-145.

Guimelli, C. (1993). Concerning the structure of social representations. Papers on Social Representations, 2(2), 85-92.

Johansson, T., \& Andreasson, J. (2016). The gym and the beach globalization, situated bodies, and Australian fitness. Journal of Contemporary Ethnography, 45(2), 143-167.

Jung, Y., \& Pawlowski, S. D. (2014). Understanding consumption in social virtual worlds: A sensemaking perspective on the consumption of virtual goods. Journal of Business Research, 67(10), 2231-2238. 
Jung, Y., \& Pawlowski, S. D. (2015). The meaning of virtual entrepreneurship in social virtual worlds. Telematics and Informatics, 32(1), 193-203.

Kickbusch, I., \& Payne, L. (2003). Twenty-first century health promotion: the public health revolution meets the wellness revolution. Health Promotion International, 18(4), 275-278.

Lacassagne, M. F., Bouchet, P., Weiss, K., \& Jebrane, A. (2004). Analyse comparative des représentations sociales du sport en France et au Maroc: valeurs modernes et post-modernes chez des étudiants en sciences du sport [Comparative analysis of social representations of sport in France and in Morocco: modern and post-modern values among students in sport sciences]. Staps, 65(3), 97-109.

Lacassagne, M. F., Pizzio, L., \& Jebrane, A. (2006). La représentation sociale du sport: vision d'étudiants sportifs et non-sportifs [The social representation of sport: the vision of athlete and non-athlete students]. Sciences \& Morticité, 58(2), 117-134.

Lebrun, A. M. (2014). Representations of a destination city break. Analysis based on free associations. Journal of Travel \& Tourism Marketing, 31, 195-210.

Lemyre, P. N., Roberts, G. C., \& Stray-Gundersen, J. (2007). Motivation, overtraining, and burnout: Can self-determined motivation predict overtraining and burnout in elite athletes? European Journal of Sport Science, 7(2), 115-126.

Mäkiniemi, J.-P., Pirttilä-Backman, A.-M., \& Pieri, M. (2011). Ethical and unethical food. Social representations among Finnish, Danish and Italian students. Appetite, 56, 495-502.

Moliner, P. (2002). Ambiguous-scenario and attribute-challenge techniques: social representations of "the firm" and "the nurse". European Review of Applied Psychology, 52, $273-279$.

Moscovici, S. (1961/2008). Psychoanalysis, its image and its public. Cambridge: Polity Press.

Moscovici, S. (1982). The coming era of representations. In J. P. Codol, \& J. P. Leyens (Eds.), Cognitive approaches to social behavior (pp. 115-150). La Haye: M. Nijhoff.

Mrazek, J., \& Schäfer, G. (1988). The Meaning of" Sport" in the Federal Republic of Germany and the USA. International Review for the Sociology of Sport, 23(2), 109-123.

Murphy, P., \& Waddington, I. (1998). Sport for all: Some public health policy issues and problems. Critical Public Health, 8(3), 193-205.

Nixon, H. L. (1992). A social network analysys of influences on athletes to play with pain and injuries. Journal of Sport \& Social Issues, 16(2), 127-135.

Pipe, A. (2001). The adverse effects of elite competition on health and well-being. Canadian Journal of Applied Physiology, 26(1), 192-201.

Podlog, L., \& Eklund, R. C. (2005). Return to sport after serious injury: a retrospective examination of motivation and psychological outcomes. Journal of Sport Rehabilitation, 14(1), 20-34. 
Pozzi, M., Fattori, F., Bocchiaro, P., \& Alfieri, S. (2014). Do the right thing! A study on social representation of obedience and disobedience. New Ideas in Psychology, 35, 18-27.

Rateau, P., Moliner, P., Guimelli, C., \& Abric, J.-C. (2011). Social representation theory. In P. A. M. Van Lange, A. W. Kruglanski, \& E. T. Higgins (Eds.), Handbook of theories of social psychology (pp. 477-487). Thousand Oaks, CA: Sage.

Roland-Lévy, C., Lemoine, J., \& Jeoffrion, C. (2014). Health and well-being at work: The hospital context. European Review of Applied Psychology, 64, 53-62.

Safai, P. (2008). Sport and health. In B. Houlihan (Ed.). Sport and society: a student introduction (pp. 165-173). London: Sage.

Sassatelli, R. (2011). Fitness culture. Gyms and the commercialisation of discipline and fun. Houndmills: Palgrave Macmillan.

Sassatelli, R. (2013). Beyond play, playfully. The cultural location of fitness activities. In F. Massimo Lo Verde, I. Modi, \& G. Cappello (Eds.), Mapping leisure across boarders (pp. 206-228). Newcastle upon Tyne: Cambridge Scholars Publishing.

Scambler, G. (2005). Sport and society: History, power and culture. Maidenhead: McGrawHill.

Segrave, J. O. (2000). Sport as escape. Journal of Sport \& Social Issues, 24(1), 61-77.

Seippel, Ø. (2006). The meanings of sport: fun, health, beauty or community?. Sport in Society, $9(1), 51-70$.

Simon, R. L. (1984). Good competition and drug-enhanced performance. Journal of the Philosophy of Sport, 11(1), 6-13.

Souchet, L., \& Girandola, F. (2013). Double foot-in-the-door, social representations, and environment: application for energy savings. Journal of Applied Social Psychology, 43(2), 306-315.

Stewart, I., \& Lacassagne, M. F. (2005). Social representations as a diagnostic tool for identifying cultural and other group differences. Psychology \& Marketing, 22(9), 721-738.

Tavani, J. L., Zenasni, F., \& Pereira-Fradin, M. (2009). Social representation of gifted children : A preliminary study in France. Gifted and Talented International, 24, 61-70.

Van-Yperen, N. W., \& Duda, J. L. (1999). Goal orientations, beliefs about success, and performance improvement among young elite Dutch soccer players. Scandinavian Journal of Medicine and Science in Sports, 9(6).

Wagner, W., Duveen, G., Farr, R., Jovchelovitch, S., Lorenzi-Cioldi, F., Markova, I., \& Rose, D. (1999). Theory and method of social representations. Asian Journal of Social Psychology, 2(1), 95-125. 
Table 1

Synthesis of the studies focused on the meaning of sport

\begin{tabular}{|c|c|c|c|}
\hline Authors & Population & Methodology & Main contents associated to sport \\
\hline $\begin{array}{l}\text { Mrazek and } \\
\text { Schäfer (1988) }\end{array}$ & $\begin{array}{l}365 \text { students from } \\
\text { two American } \\
\text { highschools and } \\
\text { two West German } \\
\text { highschools. }\end{array}$ & $\begin{array}{l}\text { word association } \\
\text { tasks }\end{array}$ & $\begin{array}{l}\text { types of sports, positive } \\
\text { evaluation, game/play/leisure, } \\
\text { training/effort, } \\
\text { achievement/competition, school. }\end{array}$ \\
\hline $\begin{array}{l}\text { Lacassagne, } \\
\text { Bouchet, Weiss, } \\
\text { and Jebrane (2004) }\end{array}$ & $\begin{array}{l}\text { Students in the } \\
\text { field of sport ( } 92 \\
\text { French students } \\
\text { and } 120 \text { Moroccan } \\
\text { students). }\end{array}$ & $\begin{array}{l}\text { word association } \\
\text { tasks }\end{array}$ & $\begin{array}{l}\text { competition, leisure, health, } \\
\text { training, activity, performance, } \\
\text { education, game, sprit of fair-play, } \\
\text { discipline, pleasure, relaxation, } \\
\text { doping, team, football. }\end{array}$ \\
\hline $\begin{array}{l}\text { Lacassagne, } \\
\text { Pizzio, and Jebrane } \\
(2006)\end{array}$ & $\begin{array}{l}92 \text { French students } \\
\text { in the field of sport } \\
\text { and } 152 \text { French } \\
\text { students in the field } \\
\text { of management. }\end{array}$ & $\begin{array}{l}\text { word association } \\
\text { tasks }\end{array}$ & $\begin{array}{l}\text { football, team, performance, } \\
\text { doping, leisure, relaxation, } \\
\text { pleasure, training, competition, } \\
\text { tiredness, effort, health, } \\
\text { togetherness. }\end{array}$ \\
\hline Seippel (2006) & $\begin{array}{l}1660 \text { members of } \\
\text { Norwegian } \\
\text { voluntary sport } \\
\text { clubs. }\end{array}$ & $\begin{array}{l}\text { list of various } \\
\text { reasons for } \\
\text { partaking in sport } \\
\text { constructed on a } \\
\text { theoretical basis }\end{array}$ & $\begin{array}{l}\text { joy/fun, keep fit, mental } \\
\text { recreation, social factors, } \\
\text { achievements/competition, } \\
\text { expressivity, body/appearance. }\end{array}$ \\
\hline
\end{tabular}


Table 2

Words associated with sport and performance as function of their potential structural status for amateur athletes

\begin{tabular}{lll}
\hline & \multicolumn{1}{c}{ Sport } & \multicolumn{1}{c}{ Performance } \\
\hline \multirow{3}{*}{ Central zone } & Pleasure $(43.7 \%, 1.86)$ & Escape $(28.5 \%, 1.11)$ \\
& Health $(42.8 \%, 1.75)$ & Pleasure $(20.4 \%, 1.44)$ \\
& Well-being $(26.8 \%, 1.91)$ & \\
\hline \multirow{3}{*}{ Peripheral zone } & Self-surpassing $(30 \%, 2.19)$ & Surpassing oneself $(39.9 \%, 2.39)$ \\
& Togetherness $(22.8 \%, 2.52)$ & Training $(35.9 \%, 2.24)$ \\
& Healthy body $(20 \%, 2.02)$ & \\
\hline
\end{tabular}

Note. Numbers between parentheses refer to the percentage of association and the average rank of appearance. 
Table 3

Words associated with sport as function of their potential structural status for professional athletes

\begin{tabular}{lll}
\hline \multicolumn{1}{c}{ Sport } & \multicolumn{1}{c}{ Performance } \\
\hline \multirow{3}{*}{ Central zone } & Pleasure $(52.3 \%, 1.97)$ & Surpassing oneself $(55.4 \%, 1.67)$ \\
& $\begin{array}{l}\text { Effort }(20 \%, 1.58) \\
\text { Sports activities (soccer, tennis, etc.) } \\
(20 \%, 1.46)\end{array}$ & $\begin{array}{l}\text { Training }(38.5 \%, 1.96) \\
\text { Effort }(30.8 \%, 1.70)\end{array}$ \\
\hline \multirow{3}{*}{ Peripheral zone } & Togetherness $(55.3 \%, 2.08)$ & \\
& Competition $(33.8 \%, 2.00)$ & Results $(24.6 \%, 2.00)$ \\
& Values $(24.6 \%, 2.00)$ & \\
\hline
\end{tabular}

Note. Numbers between parentheses are the percentage of association and the average rank of appearance. 


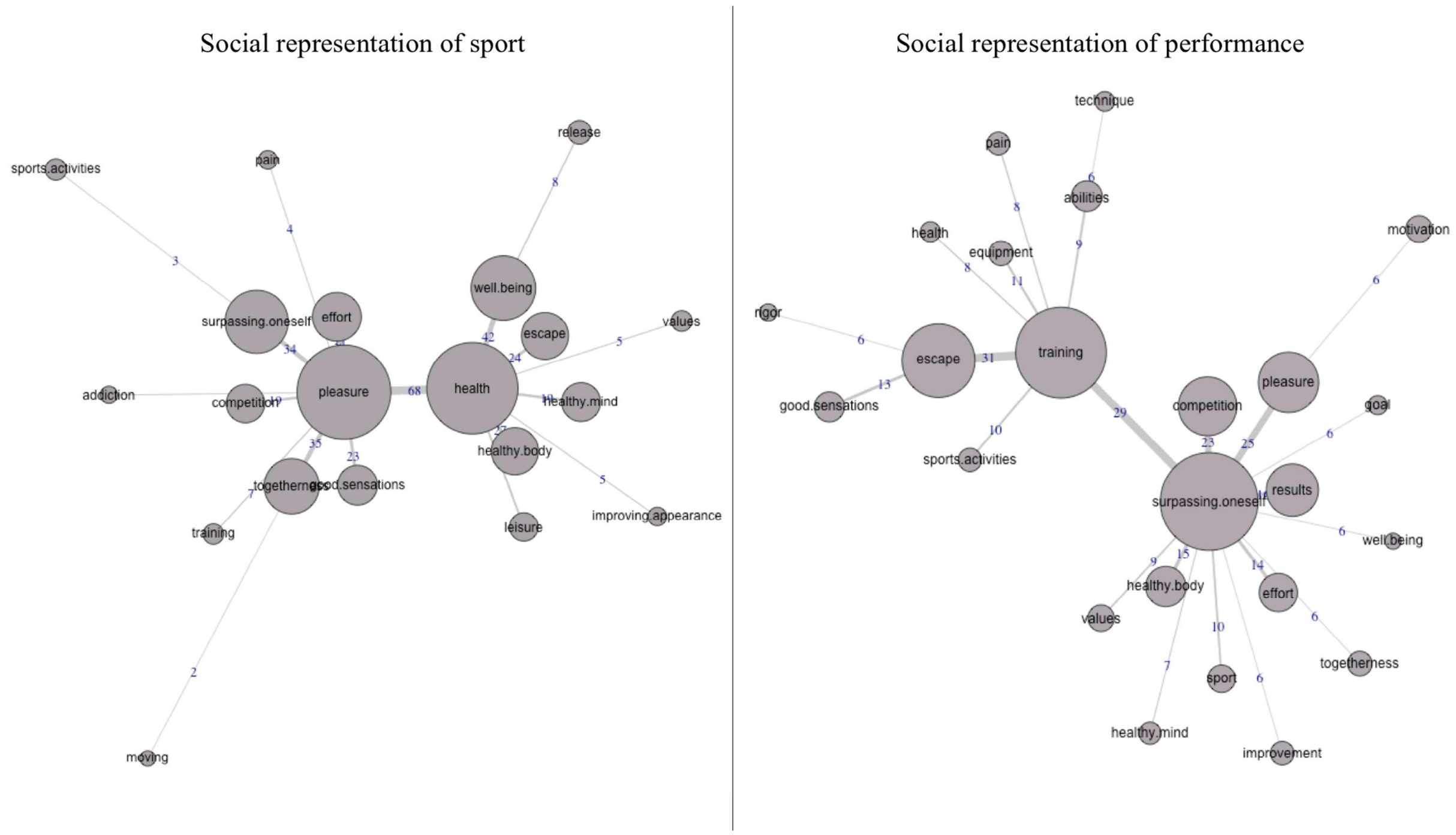

Figure 1. Social representation maps of sport and performance for amateur athletes 


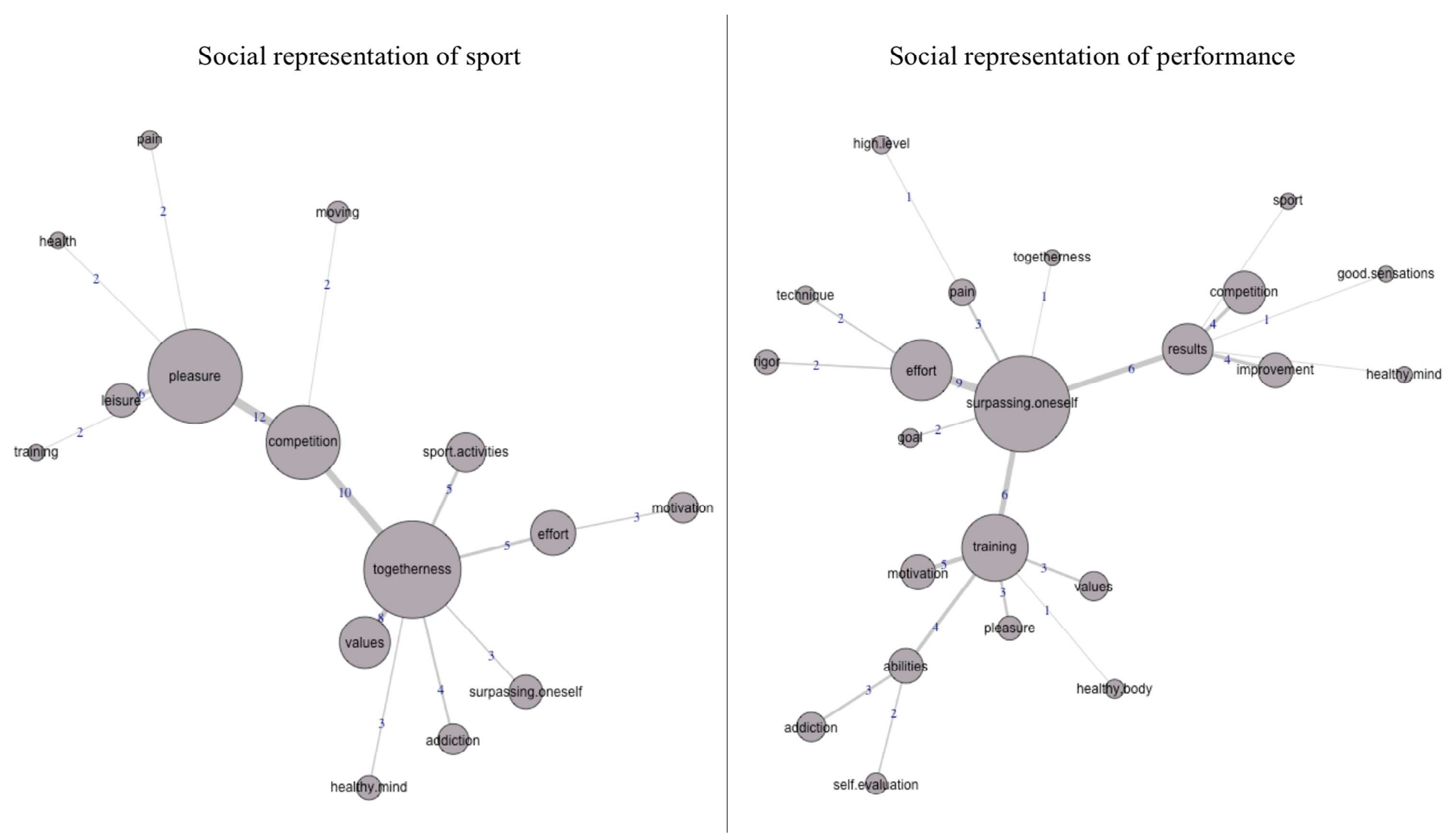

Figure 2. Social representation maps of sport and performance for professional athletes 
Dear Mr. Chatzisarantis

First of all, we would like to thank you and the reviewers for the very useful feedback and suggestions concerning the article. We have now incorporated the modifications in the attached revised version. These are detailed point by point below (each feedback/suggestion is reprised and our response/modification follows directly):

\section{Editor}

I read your manuscript and I decided that you could improve it by making some changes. Specifically, you need first to check the manuscript for grammatical errors.

The manuscript has been checked and corrected by a native English speaker.

Second you do not have any hypothesis and therefore I invite you to make specific predictions about knowledge structures and interconnections that you expect to observe.

We added an hypothesis regarding the expected differing contents of social representations of sport and performance for amateur and professional athletes page 7: "Moreover, we can draw the hypothesis that this content and its organization may differ from one group of athletes to another. Indeed, Seippel (2006) observed that competitive levels could affect the meaning attributed to sport and Lacassagne et al. (2006) showed that sport is not represented in the same way by sports students (i.e., students of the sciences and techniques of sport and physical activities) and non-sports students (i.e., students of business management). Thus, on the basis of the results of previous studies (Lacassagne et al., 2004, 2006; Mrazek and Schäfer, 1988; Seippel, 2006) content related to health and hedonism should be more associated by amateur athletes while professional athletes' social representations of sport and performance should be more oriented toward competition and the ways to achieve performance."

Third, I also think that you need to emphasise in the introduction why and how your research advances knowledge in sport. Try to be very specific, for example, you may choose previous studies as criteria and demonstrate how exactly your method and research advances those studies and therefore knowledge.

In line with this comment, we added a paragraph (page 2): "Indeed, the investigation of the meaning of sport and performance has not been extensively documented in the field of sport psychology, while in the field of the social representations theory, only a few contributions can be noted (Lacassagne, Bouchet, Weiss, \& Jebrane, 2004; Lacassagne, Pizzio, \& Jebrane, 2006; Stewart \& Lacassagne, 2005). Moreover, the results of these studies, which were only focused on the SR of sport, indicate that performance may be a complementary concept to sport and could be underpinned by specific values. Thus, through drawing on the theoretical and methodological framework of the social representation theory, this study aims to update the results related to the study of the meaning of sport (Mrazek and Schäfer, 1988). It also aims to extend the results highlighted in the field of the SRs' theory (Lacassagne, et al., 2004, 
P.2 first paragraph- $2^{\text {nd }}$ sentence, This research's contribution? Is there another word that the authors prefer to use for 'object'. It's hard to think of sport as an object.

We replaced "contribution" by "study". We also replaced "object" by "concept" when possible. However, the term "object" is usually employed in the theory of social representations. It is also part of the very definition of this concept: "systems of opinions, knowledge and beliefs particular to a culture, a social category, or a group with regards to objects in the social environment" (Rateau, Moliner, Guimelli, \& Abric, 2011, p. 478)" mentioned page 3. In this framework, the term "object" refers to social objects such as family, work, health, and so forth. Therefore, we can't see any alternative term which may be more appropriate.

\section{There are a lot of typos in the text. Please double check.}

The manuscript has been checked and corrected by a native English speaker. 
P.2. Sentence second last from end - first paragraph. What is the research is looking at; representation or associations/meanings of sport \& performance? Please clarify.

The aim of this research is to study the meaning of sport and performance through the theory of social representations. In order to clarify, we added a citation of Wagner et al. (1999) which underline the link between meaning and social representations (page 2): "In line with this social psychological theory "concerned with meaning and its interpretation" (Wagner et al., 1999, p. 104), the object does not matter and understanding the relationship to it is more important (Moscovici, 1982). From this perspective we will focus on the study of social representations (SR) of sport and performance among amateurs and professional athletes."

P. 6 method. Material and methods section. It is best use the word complete an online questionnaire rather than 'fill'. Instead of sex, the usual ethical term is gender.

Both terms have been replaced as suggested by the reviewer.

In general there needs to be more information about the word association task. A person should read this article and learn from in a stand alone form. They shouldn't go and have to look up another paper to be able to understand the method used. It can be presented briefly and then refer the reader to the more detailed description, but there must be a description included. For example, were the priming words given to the participants or they had to do free associations? Such essential information should be included in the text in this article.

We added more details in the description of the word association task. As the instructions of the word association task are very basic. The other papers mentioned do not really present more details about the procedure but rather the various forms that this procedure can take. Therefore, we also corrected our reference to these papers (page 8): "More precisely, they were asked to associate the three words "that come to their mind" concerning the term "sport" and then three words regarding the term "performance" (for an extended presentation of the procedure see Authors, 2015; Authors, 2016)" replaced by "This task consisted in asking participants to associate three words concerning the term "sport" and then three words regarding the term "performance". More precisely, "sport" and "performance" were given to participants as priming words and they were asked to write the three words "that came to their mind" in reference to each of these two terms (see Authors, 2015; Authors, 2016).".

P.10. Last line - what does actually self-surpassing really means here?

This term has been replaced by "surpassing oneself". We clarified its meaning of this page 10 (when it is mentioned for the first time): "Other elements such as "surpassing oneself" (i.e., overcoming one's own limitations) and "togetherness" are also associated by participants." 
Further more, as a project aimed at such synthesis, a more thorough systematic review or even a meta-analysis of previous studies would have provided better context of the question that is being addressed.

The main aim of this research project is to update the results related to the study of the meaning of sport and to extend the results highlighted in the field of the social representations theory by taking into account the concept of performance and the population of professional athletes for whom this object constitutes an important stake in the practice of sport. In this perspective we conducted a thorough search of the references focused on the study of meaning and/or social representations of sport and/or performance using the main databases available. However, as we mentioned in our contribution (page 4): "the investigation of meaning has not been extensively documented in the field of sports psychology (Mrazek \& Schäfer, 1988; Seippel, 2006). However, a few contributions can be noted (see Table 1).". As a consequence, we provided information about the methodologies and results of these few studies in order to justify the necessity to extend them and consider the population of professional athletes. In order to provide a better synthesis, we added a synthetic table page 5 . 